\title{
THE PREMOTOR CORTEX OF THE MONKEY ${ }^{1}$
}

\author{
MICHAEL WEINRICH AND STEVEN P. WISE ${ }^{2}$ \\ Laboratory of Neurophysiology, National Institute of Mental Health, Bethesda, Maryland 20205 \\ Received November 23, 1981; Revised March 25, 1982; Accepted March 26, 1982
}

\begin{abstract}
The relationship of single unit activity to limb movements guided by visuospatial cues supports the view that the premotor cortex is a distinct cortical field within the somatic sensorimotor cortex. The premotor cortex is similar to the precentral motor cortex (MI) in that most of its units are clearly related to voluntary movements but differs from MI by its higher threshold for microstimulation-evoked movements, its cytoarchitecture, and the presence of a larger population of neurons with activity related to the occurrence of visuospatial signals rather than, or in addition to, the movement cued by those signals.
\end{abstract}

The concept of a distinct premotor cortical field within the larger frontal agranular cortex arose from the work of Bucy (1933, 1935) and Fulton (1934). The premotor cortex can be defined as the part of the frontal agranular isocortex outside of the precentral motor (MI) and the supplementary motor (MII) representations and it can be distinguished from the rostrally adjacent frontal granular cortex on cytoarchitectonic grounds. This definition is consistent with the earliest views of the premotor cortex (e.g., Bucy and Fulton, 1933; Bucy, 1935) as well as with recent reviews by Humphrey $(1979)^{3}$ and Wiesendanger (1981).

The work of Kubota and Hamada (1978) supports the idea that the premotor cortex has a motor function but leaves open questions concerning the precise location of premotor cortex neurons that are related to visually guided movements and the distinction between the premotor cortex and MI. Moreover, previous investigators have not examined neuronal activity during a period in which the monkey has become set to make a particular movement on the basis of a visuospatial cue but is delaying execution of the movement pending a subsequent triggering cue. Information about premotor cortical activity prior to movement execution is especially

\footnotetext{
${ }^{1}$ We would like to thank Dr. E. V. Evarts for his help in all phases of the present study, Mr. W. Burris for technical assistance, Dr. J. Tanji for his comments, and Mrs. D. Bender for preparation of the manuscript.

${ }^{2}$ To whom correspondence should be addressed at Building 36 , Room 2D10, Laboratory of Neurophysiology, National Institute of Mental Health, Bethesda, MD 20205.

${ }^{3}$ Premotor cortex, as we use the term, corresponds to Humphrey's (1979) use of the term " $6 a \beta$ " and should not be confused with any part of "area 6" which may be included within the MI representation of Woolsey et al. (1952). See also Fetz et al. (1980) and Kwan et al. (1978) who use the term "area 6 " for the most rostral part of MI.
}

important in view of the proposal of Roland et al. (1980) that the premotor cortex in man "is activated when a new motor program is established ... or when the motor program is changed on the basis of sensory information."

\section{Materials and Methods}

Behavioral paradigm. Two male rhesus monkeys (Macaca mulatta), 7 and $9 \mathrm{~kg}$, were used in the present experiments. Although the motor tasks for the two monkeys were somewhat different, the basic behavioral patterns were comparable. The description of methods and results will focus on one of these animals. However, all of the conclusions and observations agree with the data obtained from both monkeys. The first of the two monkeys was operantly conditioned to press a series of keys in response to visual and auditory cues while seated in a primate chair. Four keys were located on a table at arm's length and were separated by $20^{\circ}$ with respect to the monkey's body axis. (see Fig. 1). While the monkey depressed one of these keys (part 1, Fig. 1), one of the other three keys, selected randomly, was illuminated (part 2, Fig. 1). The illuminated key served as the next target key and its illumination served as the "ready" signal as well as an instruction concerning the next movement which would be required. After the ready signal, the monkey was required to remain in his original position (start key) for one of eight randomly determined "delay" periods ( 0.8 to $2.4 \mathrm{sec}$ ) after which a visual "go" signal was delivered and the monkey was free to lift-off the starting key and depress the target key (part 3, Fig. 1). The go signal was a light-emitting diode immediately in front of the target key. The intensity of the go signal was adjusted during conditioning in order to require at least approximate fixation on the light-emitting diode to detect its illumination. The monkey was required to make a rapid, reaction time movement, with only 600 
INTER-TRIAL:
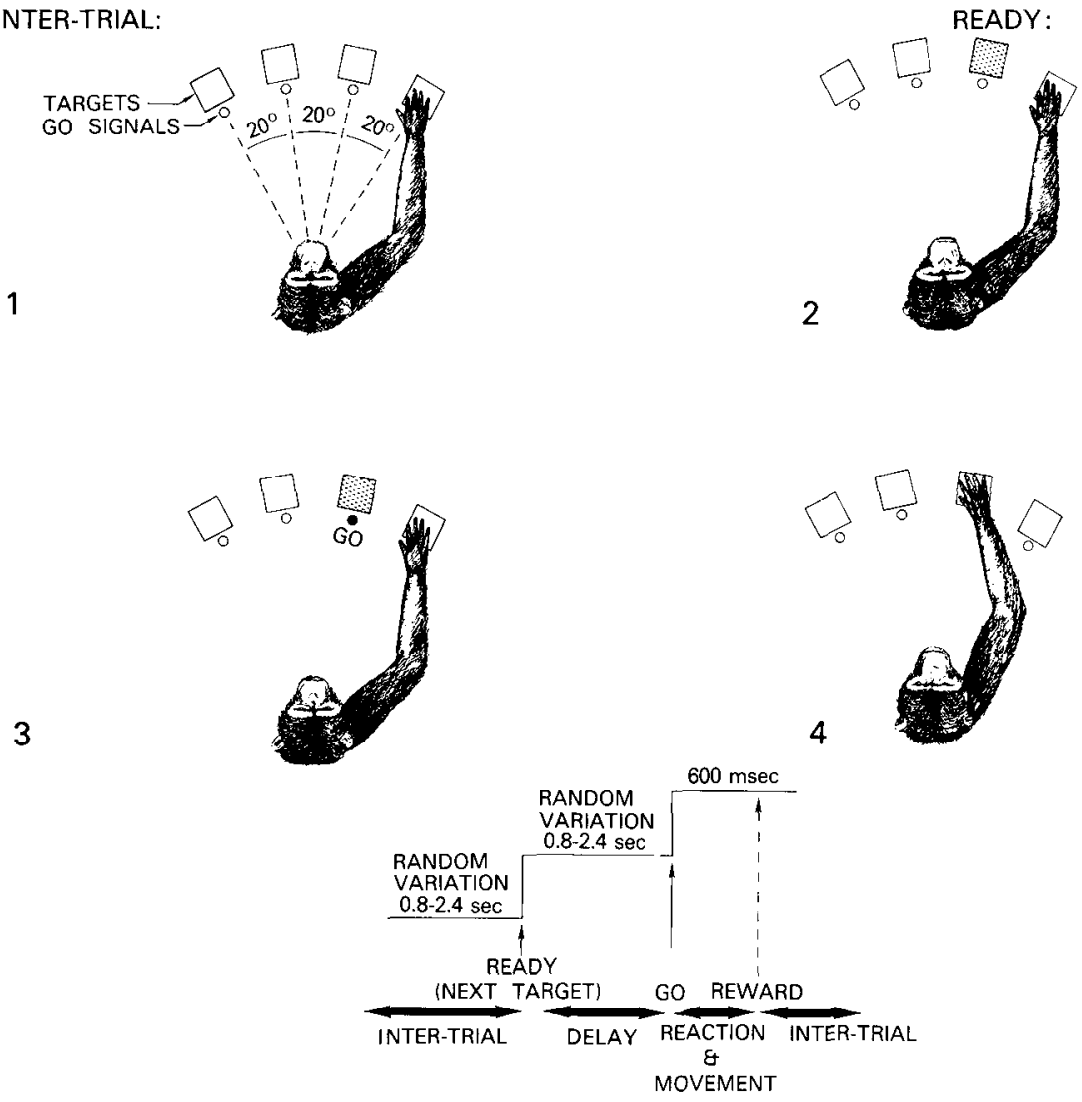

Figure 1. Behavioral paradigm. Parts 1 to 4 show the sequence of visuospatial signal presentation and motor activity. See the text for description.

msec allowed from the onset time of the go signal to reach the target key (part 4, Fig. 1). Depression of the target key, regardless of whether it was rewarded, was followed by one of eight randomly determined "intertrial intervals" ( 0.8 to $2.4 \mathrm{sec})$ during which the monkey was required to continue depressing the key ( parts 1 and 4, Fig. 1). This cycle was repeated 40 to 150 times for each single unit accepted for analysis.

The second task studied in the first monkey was similar to the first. The major difference was that the target key was not illuminated. Instead, an auditory signal (a $1-\mathrm{kHz}$ tone) located directly behind the target key served as the ready signal and instruction.

The second of the two monkeys was conditioned to perform a similar task but one in which flexion and extension around the elbow controlled a visual display in front of the animal. These tasks were designed to elicit rapid visually guided arm movements: the key-pressing task to involve a large group of arm muscles and the elbow flexion-extension task to allow continuous monitoring of arm position.

Recording methods. A stainless steel recording chamber $(18 \times 36 \mathrm{~mm})$ was cemented to the skull and head bolts were implanted while the animals were anesthetized with sodium pentobarbital. The usual chronic single unit recording methods were employed. Units were isolated with 1 - to 3 -megohm (at $1 \mathrm{kHz}$ ) glass-insulated platinum/ iridium electrodes penetrating the cortex transdurally. Unit and behavioral data were analyzed off-line with PDP-12 or PDP-11/34 computers. No drugs were given to the animals during the daily recording sessions.
Muscle activity (EMG) was monitored with surface cup electrodes or subcutaneous tungsten wire electrodes. The EMG potentials were full wave rectified, converted from voltage to frequency, and analyzed in the same manner as the single units. The horizontal electro-oculogram (EOG) was monitored with silver/silver chloride cup electrodes implanted in the temporal bones.

Units were recorded while the head was fixed. Saccades were detected by window discrimination of the differentiated EOG signal. Torque produced during attempted head movements was monitored by strain gauges mounted on the axis of the head restraint apparatus. All single unit recordings were made from the right hemisphere and the key press was performed with the left arm for all units.

Microstimulation technique. Intracortical microstimulation was performed during most penetrations at the depth where the largest amplitude unit potentials were observed (the presumptive layer V). A train of 11 constant current, cathodal pulses of $0.2 \mathrm{msec}$ duration at 333 pulses/sec was used to evoke movements or muscle twitches. The animals were examined for either observable limb movements or muscle twitches, but no EMG recording of microstimulation effects was attempted. Threshold was defined as the current intensity at which movement was evoked by about half of the shock trains. Current intensity never exceeded $60 \mu \mathrm{A}$ and was verified periodically by measuring the voltage drop across a 10 kilohm resistor in series with the animal.

Analytical procedures. Unit activity was displayed, in raster form, relative to a number of behavioral events: 


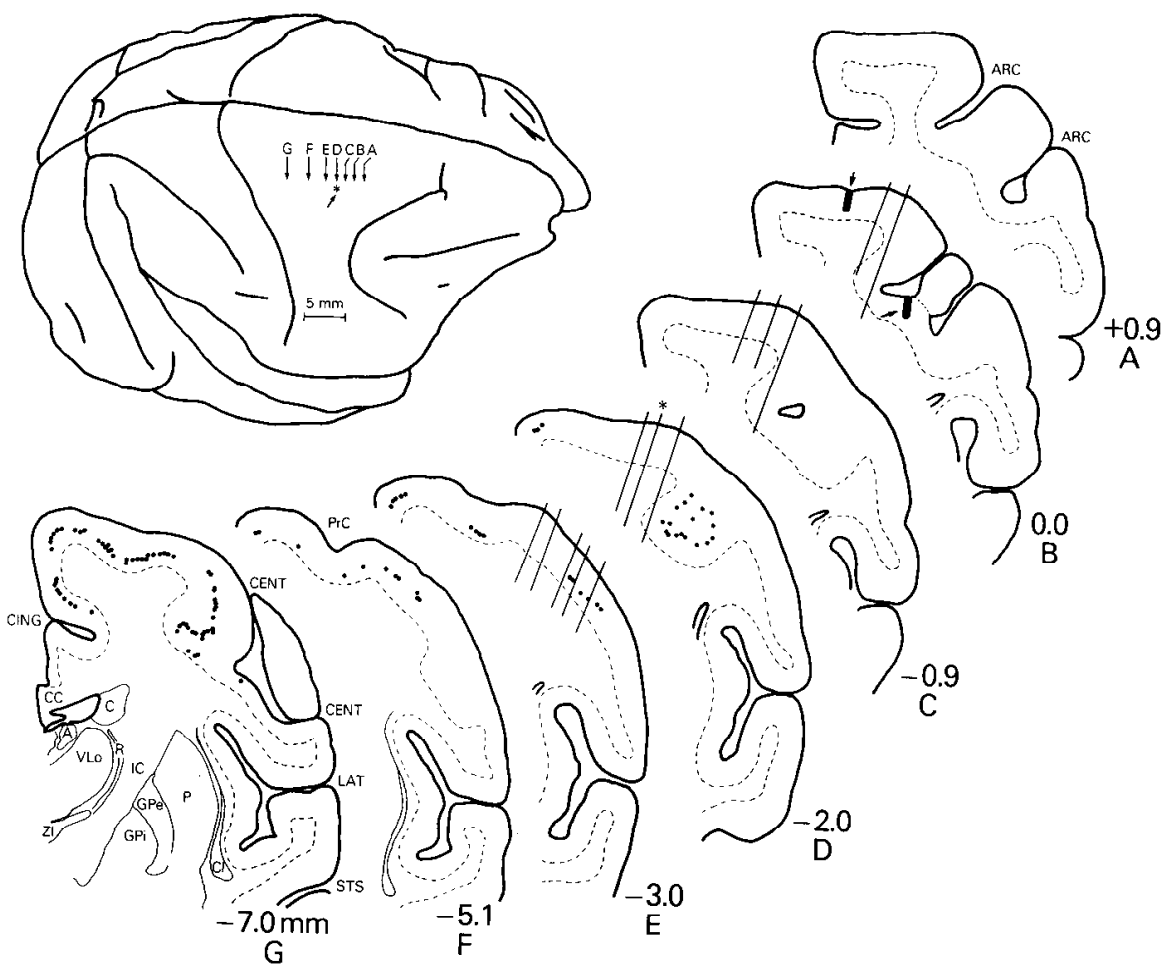

Figure 2. Histological reconstruction. A surface view of the brain shows the location of frontal sections $A$ to $G$. The asterisk on the brain marks the location of the penetration similarly marked in section $D$ and the penetrations marked with an arrow in Figure 3. The number above each letter is the distance in millimeters of that section from the genu of the arcuate sulcus. The negative numbers indicate sections caudal to the arcuate genu. The solid circles in the sections mark the location of giant layer $\mathrm{V}$ pyramidal cells. The premotor cortex penetrations with the largest number of set-, signal-, and movement-related units are indicated by straight lines. The abbreviations for sulci are: $A R C$, arcuate; $C E N T$, central; $C I N G$, cingulate; $L A T$, lateral; $P r C$, precentral; $S T S$, superior temporal. The abbreviations for nuclei and tracts are: $A$, anterior group of thalamic nuclei; $C$, caudate; $C C$, corpus callosum; $C l$, claustrum; $G P e$, external segment of globus pallidus; $G P i$, pallidal internal segment; $I C$, internal capsule; $P$, putamen; $R$, reticular nucleus of the thalamus; $V L o$, rostral part of the ventrolateral nucleus; $Z I$, zona incerta. The arrows indicate marking penetrations.

the "ready" signal, the "go" signal, the release of the start key (which closely approximated the onset of movement), the depression of the target key (which signaled the termination of the dynamic phase of motor activity), and saccadic eye movements. The modulation of unit activity in relation to these events was determined with an average reciprocal interval (instantaneous frequency) plot taken for 20 to 36 trials. The onset of modulation was determined by visually estimating the time of deviation of the neuronal firing rate from activity during the "delay" period and was verified for 24 of the most clearly modulated units with a Poisson statistical routine described in the DECUS library. ${ }^{4}$ In general, the visual assessment indicated activity changes 5 to $15 \mathrm{msec}$ earlier than the statistical program, but in all units accepted for analysis, the change in unit activity was statistically significant at the $p<0.05$ level. The same analysis was used for muscle activity.

Histological methods. 'T'he animals were given an overdose of pentobarbital and perfused first with isotonic saline and then with $10 \%$ formol/saline. After several pins were inserted temporarily at known electrode coordinates, the brains were removed from the skull, photo-

\footnotetext{
${ }^{4}$ Details of all statistical procedures employed are available from the DECUS program library of the Digital Equipment Corp., Marlboro, MA, No. 12-65: "NAP systems program to analyze spike activity."
}

graphed, and postfixed for 2 weeks. One brain was embedded in celloidin, sectioned at $40 \mu \mathrm{m}$, and stained for Nissl substance with $0.05 \%$ thionin. The other brain was sectioned on a freezing microtome at $25 \mu \mathrm{m}$ and stained in a similar manner.

As part of the cytoarchitectonic analysis, the number of cells which measured greater than $29 \mu \mathrm{m}$ across the base of the cell body and had visible nucleoli was determined in a series of frontal sections. Flectrode tracks were plotted relative to the marking sites (Fig. 2) and the histologically observable extreme penetration tracks. No effort was made to identify individual electrode tracks or the layer in which the units were located since the error in depth measurements in these chronic preparations is large relative to the thickness of cortical laminae. Units were plotted on the basis of their recorded depth in a penetration and the depth of the subcortical white matter, which usually could be identified by an abrupt reduction of neuronal activity.

\section{Results}

\section{Behavioral observations}

Arm movements. The mean reaction time of the monkey, defined as the time between the go signal and liftoff from the start key, was $300 \pm 11 \mathrm{msec}$ (SD). The low variance in reaction time resulted from an extended 

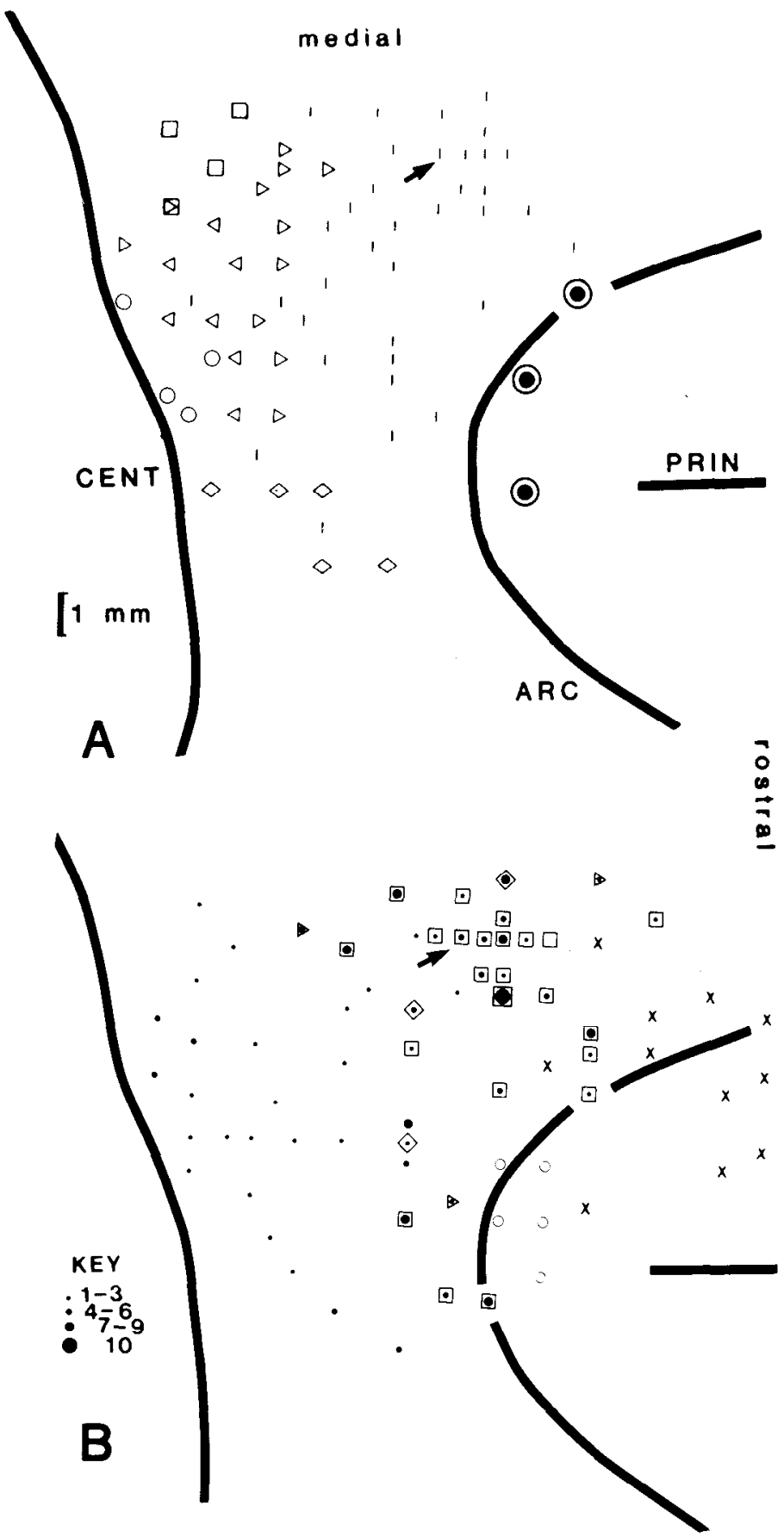

Figure 3. Surface reconstructions of intracortical microstimulation results $(A)$ and the location of task-related units $(B)$ in one monkey. $A$, Sites with microstimulation thresholds exceeding the maximum current applied $(60 \mu \mathrm{A})$ are indicated by the vertical bars; positive sites at less than this stimulation level are indicated by the open symbols: square, shoulder; triangles pointing left, elbow; triangles pointing right, wrist; circles, digits; diamonds, face; filled circle within a circle, eye movements. B, Filled circles mark the penetrations with movementrelated cells. The size of the filled circle indicates the approximate number of movement-related units in each penetration. Open squares mark the penetrations with both signal- and setrelated units; open triangles, signal-related units; open diamonds, set-related units; $\times$, no task-related units; open circles, saccade-related units. The arrow marks the same penetration in $A$ and $B$, which is the asterisk-marked penetration in Figure 2. Those units within the high threshold microstimulation conditioning period which allowed the monkey to achieve a remarkably stable task performance. The mean movement time, defined as the time between lift-off of the start key and depression of the target key, was $173 \pm 23$ msec. The monkey failed to perform the task correctly on only about $5 \%$ of the trials.

EMG recordings in the first monkey showed no evidence of any transient or sustained increase in activity following the ready signals in biceps, triceps, rhomboids, deltoids, trapezius, or latissimus dorsi. In the second monkey, in addition to those muscles, teres major, cervical and lumbar paravertebral muscles, pectoralis major, extensor carpi ulnaris, extensor carpi radialis, flexor carpi radialis, brachialis, and brachioradials were monitored, many bilaterally, and they also showed no consistent transient or sustained relationship with the ready signal. EMG activity was synchronized with movement; the earliest muscles were activated 20 to $80 \mathrm{msec}$ before movement onset. The onset times of selected muscles in the first monkey are indicated by the horizontal arrows in Figure 7.

Eye movements. The appearance of the visual ready signal elicited saccades to the target. The monkey fixated the target throughout the delay and movement phases of the trial for approximately $30 \%$ of the successful trials. In the other successful trials, he made small saccades (less than $5^{\circ}$ ) in the vicinity of the target. Instances in which he made large, off-target saccades within $500 \mathrm{msec}$ of the go signal were almost always associated with unrewarded trials and were eliminated from the present analysis. The monkey rarely moved his eyes during the movement phase of the trial. Thus, eye and arm movements to the target were dissociated temporally. Eye movements during the task in which the auditory ready signal was used were similar, although the monkey made more small saccades in the vicinity of the target during the delay period. Changes of torque on the head-holding apparatus did not occur in association with eye movements during any phase of the trials.

\section{Cortical field definition}

Microstimulation effects. The premotor cortex can be distinguished from the MI representation by its markedly higher threshold for eliciting muscle contractions with intracortical microstimulation. Figure $3 A$ shows that, when the stimulating electrode was within approximately $3.5 \mathrm{~mm}$ of the genu of the arcuate sulcus and the stimulus strength was below $60 \mu \mathrm{A}$, movements or muscle twitches were only very rarely observed. No effect was observed at $60 \mu \mathrm{A}$ in 25 of the 26 tested penetrations in this part of the cortex. There was a transition zone extending from 3.5 to $5.0 \mathrm{~mm}$ caudal to the arcuate genu in which both positive (3) and negative (7) sites were found. In a yet more caudal region, greater than $5 \mathrm{~mm}$ caudal to the arcuate genu, 26 of 29 tested penetrations yielded microstimulation effects at low thresholds. The thresholds for these effects were typically 10 to $30 \mu \mathrm{A}$ and, occasionally, as low as $5 \mu \mathrm{A}$. Shoulder protraction or retraction, axial

region were considered to be in the premotor cortex. The abbreviations for sulci are: $A R C$, arcuate; $C E N T$, central; $P R I N$, principal. 
deviation, elbow flexion or extension, digit flexion, and lip retraction (Fig. $3 A$ ) were observed. We chose $60 \mu \mathrm{A}$ as the maximum stimulation level because this level of current is well above that usually needed to elicit effects from MI (Kwan et al., 1978). Single unit recording before and after microstimulation confirmed that this level of stimulation did not cause any appreciable damage.

Cytoarchitectonic analysis. The part of the cortex with microstimulation thresholds consistently lower than 60 $\mu \mathrm{A}$ (the MI cortex) had a high concentration of giant layer $\mathrm{V}$ pyramidal cells, whereas the region requiring stronger stimulation (the premotor cortex) had a lower concentration of giant layer $\mathrm{V}$ cells. The number of neurons with a basal diameter exceeding $29 \mu \mathrm{m}$ was determined in a 3.6-mm width of cortex in each of 62 frontal sections. Width here refers to the horizontal dimension of the cortex, that tangential to the pial surface. The most rostral of these sections was $1.5 \mathrm{~mm}$ rostral to the genu of the arcuate sulcus (here termed the $+1.5-\mathrm{mm}$ level; see Fig. 2) and the most caudal section was $8.5 \mathrm{~mm}$ caudal to the arcuate genu (the $-8.5-\mathrm{mm}$ level). The 3.6$\mathrm{mm}$-wide region examined in each section was centered
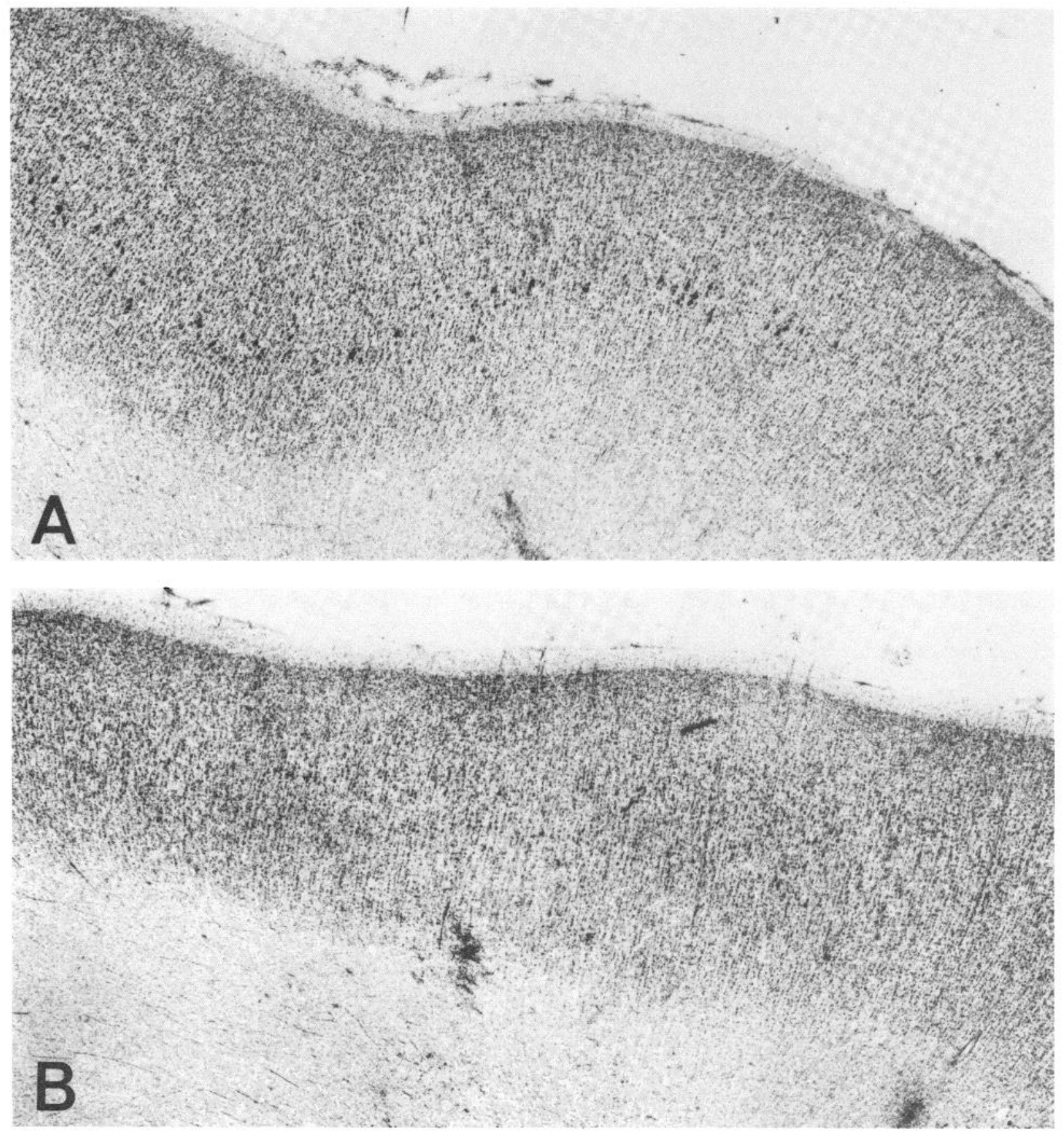

Figure 4. Photomicrographs of Nissl-stained frontal sections centered on the mediolateral level marked by the asterish in Figure $2 D$. Photomicrograph $A$ is taken from the low threshold microstimulation zone (see Fig. $3 A$ ) $4 \mathrm{~mm}$ caudal to $B$. $B$ is taken from the rostrocaudal level marked by the arrow in Figure 3 and the asterisk in Figure 2 . This was the high threshold microstimulation zone. Note the relative lack of giant layer V pyramidal cells in $B$ and their high density in $A$. 
at the mediolateral level marked with an arrow in Figure 3 . Rostral to that penetration (from the -2.0 - to the +1.5 -mm levels), no sections contained more than 3 giant pyramidal cells; the mean was $2.6 \pm 2.4$ giant cells per $3.6-\mathrm{mm}$ width of cortex (see Fig. $4 B$ ). These few giant cells were not clustered. In the caudal region, where consistently positive microstimulation effects could be elicited at less than $60 \mu \mathrm{A}$ (from the -5.0 - to the -8.5 $\mathrm{mm}$ levels), between 6 and 22 giant neurons were found in each 3.6-mm width of section (see Fig. $4 A$ ); the mean was $13.8 \pm 4.3$ giant neurons. These cells often were clustered in small groups of 3 to 5 . Between the two regions, an intermediate number of giant cells (2 to 8 ) was observed. No sharp transition in giant cell number was found, and in these intermediate sections, the giant pyramidal cells often were clustered in a single group. Thus, a large number of giant pyramidal cells was observed in sections representing a rostrocaudal level at which low threshold microstimulation effects could be found $(Z=-6.1 ; p<<0.001$; Mann-Whitney $U$ test, two tailed). Further, the number of giant cells in a section correlated closely with the rostrocaudal level of that section $(r=-0.89 ; p<0.001$; Pearsonian correlation coefficient). That is, the more caudal the section, the larger was the observed number of giant pyramidal cells in layer $\mathrm{V}$.

\section{Premotor cortex: Unit classification}

Two hundred five single units in the premotor cortex related to the behavioral task were studied. Units were classified on the basis of their activity in relation to ready and go signals, movement onset, and target acquisition. Base line (resting) activity was defined as the neuronal firing frequency during the inter-trial intervals (see the introduction; Fig. 1). Signal-related units were defined as units with bursts of activity synchronized with and following either the auditory or visual ready signal. Setrelated units were defined as units demonstrating a sustained change in activity during the delay period (see Fig. 1) compared with the activity level seen in the intertrial intervals. Movement-related units were defined as units with changes in activity (compared with activity levels during both the inter-trial interval and the delay period) synchronized with movement onset. A cell was classed as a movement-related unit if its activity satisfied this definition consistently for movements in one direction, or to a particular target, even if it failed to meet these criteria for other movements. The frequency distribution of units classed according to these criteria is given in Table I. (Note that these classes are not mutually exclusive. Many units satisfied the definitions of more than one class). None of the units in these classes showed any relationship with saccadic eye movements.

Movement-related units. Most task-related units in the premotor cortex $(149 / 205 ; 73 \%)$ exhibited high frequency, phasic bursts of activity in relation to movement. These bursts were synchronized with the onset of voluntary movements and generally began before movement onset. The units typically were excited in relation to movement (123 neurons) although some were inhibited (26 neurons). The excited units reached a mean peak frequency of $79.9 \pm 43.8 \mathrm{impulses} / \mathrm{sec}$. Their activity
TABLE I

Unit classes in the premotor cortex

\begin{tabular}{llrr}
\hline \multicolumn{1}{c}{ Class } & \multicolumn{1}{c}{ Combinations } & $N$ & Percent \\
\hline Signal & Only & 22 & 11 \\
& + Set & 14 & 7 \\
& + Movement & 22 & 11 \\
& + Set + movement & 31 & 15 \\
& Total & 89 & 43 \\
& Only & & \\
Set & + Signal & 8 & 4 \\
& + Movement & 14 & 7 \\
& + Signal + movement & 31 & 3 \\
& Total & 15 \\
& Only & 59 & 29 \\
Movement & + Signal & 91 & 45 \\
& + Set & 22 & 11 \\
& + Signal + set & 6 & 3 \\
& Total & 31 & 15 \\
& & 149 & 73 \\
Total & & & \\
& & 8 & 4 \\
\hline
\end{tabular}

during the inter-trial interval averaged $7.7 \pm 5.5 \mathrm{im}$ pulses/sec. The $95 \%$ confidence limil for these units was 69.8 to 90.1 impulses/sec and the range was 12 to 225 impulses/sec. Representative movement-related units are illustrated in Figure 5. Note that, for each of the 6 units shown in Figure 5, unit activity (as displayed in the rasters) was modulated before and in temporal correlation with the onset of movement (solid arrows). Movement-related units were consistently more closely synchronized with time of key release than the appearance of the go cue (Fig. 6). Four additional units showed activity related to the visual go cue. These units were synchronized with the go signal and preceded arm movement by much longer periods ( 250 to $350 \mathrm{msec}$ ) than movement-related neurons. These cells were classed as signal-related units rather than movement-related units since they invariably "responded" to the visual ready cue and the go signal at the same latency. No movementrelated units discharged in relation to the reward or the monkey's licking.

Changes in the activity of motor-related units (termed unit onset) preceded movement onset by as much as 220 msec with a mean of $130 \pm 60$ msec. A comparison of unit onset times with EMG onset in arm and shoulder muscles is shown in Figure 7 . The unit onset times precede the earliest EMG activity by a mean of $50 \mathrm{msec}$ and by as much as 140 msec. The activity changes lasted a mean of 418 msec. Most (59\%) movement-related units were active during the full duration of movement (and for a mean of $115 \mathrm{msec}$ after the termination of movement).

A substantial population of movement-related units $(57 / 149 ; 38 \%)$ was directionally sensitive. Directional sensitivity occurred in three patterns. Most commonly (38 units), these units showed altered discharge with movement only in one direction and no change with movement in the opposite direction (Fig. 8). Fourteen units showed 

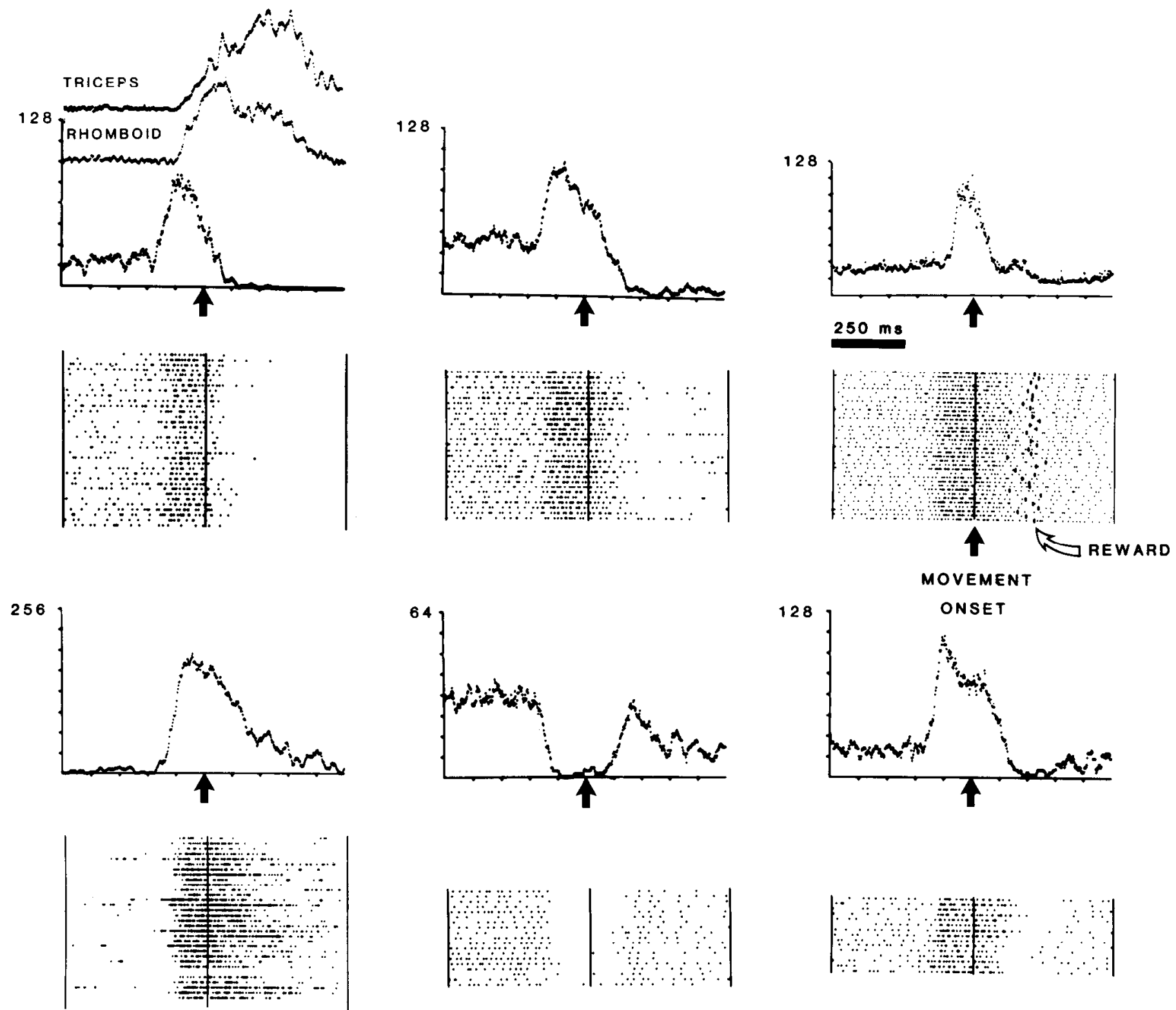

Figure 5. Activity patterns of 6 different premotor cortex units. Each line of the raster represents unit activity during one movement and is centered on movement onset (arrous) with the corresponding reciprocal interval plot for the summed trials shown above the raster. The dots represent the occurrence of action potentials. EMG activity for the two muscles which show the earliest changes in activity in relation to movement onset is shown for comparison above the top left reciprocal interval plot. Note the magnitude of unit modulation and that the top left unit reaches an activity peak at about the time of the earliest EMG changes. The numbers on the ordinate represent impulses per sec.

greater modulation with movements in one direction than the other. Five units were classed as directional since they became active before movement in one direction and after movements in the opposite direction. Comparable numbers of flexion movement-related and extension movement-related cells were observed. Ninety-four of the 149 movement-related units were nondirectional (i.e. they discharged comparably with flexion or extension movements). Only 2 of the movement-related neurons appeared to be specific for movements to a certain position, rather than movement direction, and these findings were equivocal. No relationship was noted between the activity of movement-related units and the spatial hemifield in which the movement began or terminated.
Even though there may be visual input to this region of the cortex, the movement-related activity cannot be attributed simply to visual stimuli, such as the visual cues presented in our experiment or the movement of the arm within the monkey's visual space. First, the units were temporally better correlated with arm movements than any visual cue. Further, unit activity almost always precedes arm movement; therefore, movement of the arm within the visual field cannot be a cause of the earliest aspect of movement-related activity. Finaliy, in our second paradigm, the one in which the auditory ready signal was used, movements were made in virtually total darkness, and under this condition, the movementrelated unit activity remained the same as when the 

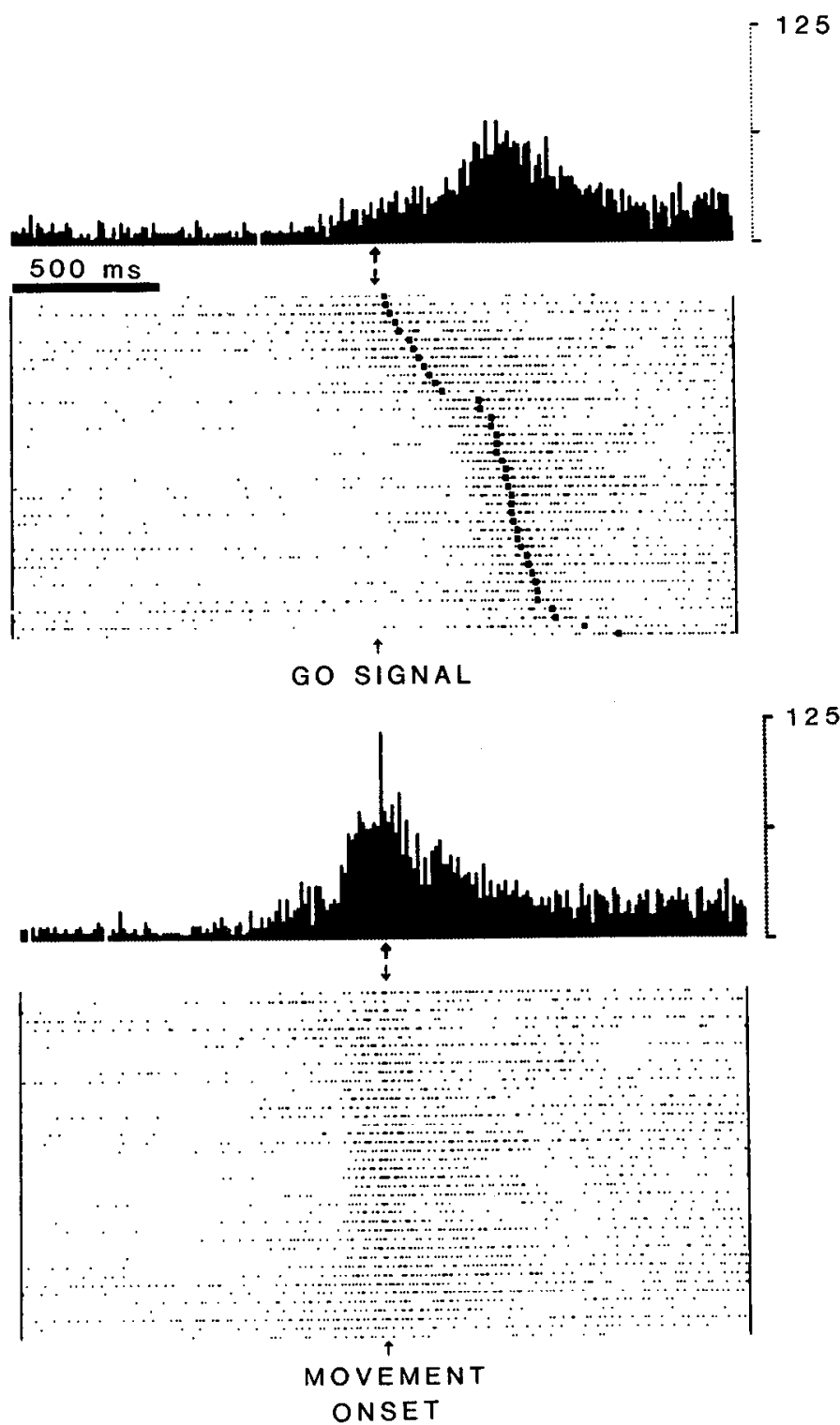

Figure 6. Relationship between unit activity and either the go signal (top) or movement onset (bottom) for a premotor cortex unit. Note the better temporal correlation with movement onset than with the go cue. In the top raster, movement onset is indicated by the heavy marks to the right of the center. The unit was recorded in the second monkey in which the variation in reaction time was much greater and the motor task was somewhat different from that for the first monkey (see "Materials and Methods").

visual ready signal was presented. The movement-related activity could not be attributed to eye movements or attempted head movements since unit activity did not correlate with these behaviors.

Signal-related units. Eighty-nine units (43\%) showed distinct phasic activity following the visual and auditory ready cues at $135 \pm 38$ msec latency. The mean peak signal-related activity was $39.3 \pm 23.5$ impulses/sec (background subtracted), while the range was 7 to 71 impulses/sec. Eighty-seven units were specific for the visual ready cue (Fig. 9), 2 for the auditory ready cue, and none for both. We did not attempt to test the visual receptive fields of these neurons. There was no evidence of increased EMG activity in relation to the cue to indicate a generalized startle effect. EMG activity during and after the ready cue is illustrated in Figure 10.

Set-relaled unils. Fifty-nine units (29\%) exhibited setrelated activity. The mean latency between the ready cue and the onset of set-related neuronal activity was 173 $\pm 26 \mathrm{msec}$. Set-related activity, as defined by the absolute value of the difference between activity during the delay period and that during the inter-trial interval, usually did not reach the levels typical of movements-related activity, although tonic activity levels of up to 70 to 83 impulses/sec were observed in 4 units. The mean setrelated activity level was $32.2 \pm 20.0$ impulses/sec and the $95 \%$ confidence limit was 26.9 to 37.5 impulses/sec. Those set-related units excited during the delay period (see below) reach a mean of $44.0 \pm 21.2$ impulses/sec (95\% confidence limit; 37.9 to 50.2 impulses/sec), while their mean activity during the inter-trial interval was $10.6 \pm 9.8$ impulses/sec. No unit was accepted as a setrelated unit if the activity during the delay period failed to change by at least 7 impulses/sec.

Most (52) set units maintained a nearly constant firing rate throughout the delay period. Thus, after the ready signal (left arrow in Fig. 11A), the activity increased and later returned to resting levels of discharge only after the onset of movement (right vertical arrow in Fig. 11A). A few (7), increased their discharge rate continuously as the delay between ready and go cues increased. Only 2 units showed inhibitory set activity for all movement directions. Thirty-five set-related units were tested with both visual and auditory ready signals. Most set units (19) showed a similar relationship to both signals (Fig. 12). However, some set-related units appeared to be specific for either auditory (8) or visual (8) rcady cues.

Most set-related neurons $(36 / 59 ; 61 \%)$ showed specificity for the direction of the upcoming movement (Fig. 11). Some (10) were excited before movements in one direction while inhibited before movements of the opposite direction (see upper left versus lower left panels of Fig. 12). The remaining directionally specific, set-related units (26) showed greater changes before movements of one direction than the other (Fig. 13). In only two equivocal cases did the activity of set-related units appear to be specific to the ultimate target of the movement rather than movement direction. The set-related activity did not reflect the appearance of the visual ready signal in a certain part of the visual field since $(a)$ the same patterns were observed when the auditory ready signal was used and $(b)$ the visual ready signal did not appear in any fixed relation to the fovea. Nor did set-related activity reflect visual fixation since the animal broke fixation often during individual trials and this was not reflected in the unit activity. The absence of any observable change in EMG activity in the muscles tested during the delay period (see Fig. 10) precludes generalized co-contraction or muscle tensing as a behavioral correlate of set unit activity. We conclude therefore that the set-related activity reflects the motor set or motor planning. We cannot exclude, however, the possibility that some muscle which we did not monitor changed during the delay period in the same manner as the set-related units, although we have sampled a wide variety of proximal, 


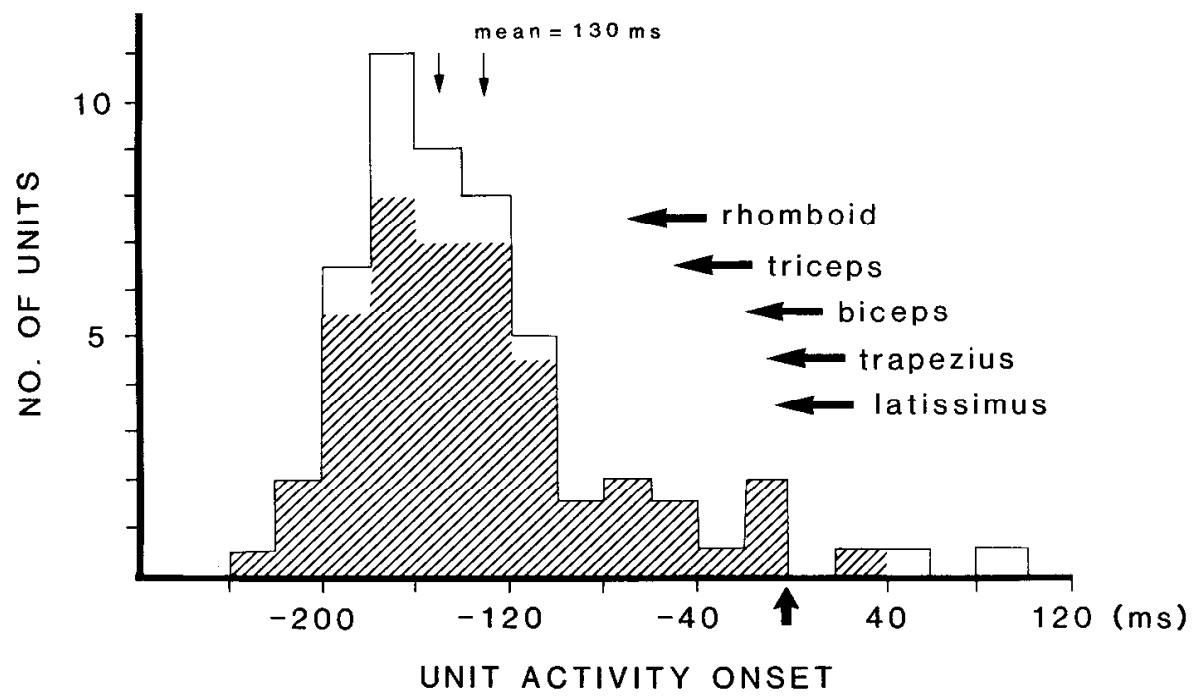

Figure 7. Unit activity onset time in relation to movement onset and the earliest changes in EMG activity. The hatched area represents units clearly within the premotor cortex. The open area includes units near the border between MI and the premotor cortex. The large horizontal arrows point to the onset of EMG activity increase in representative muscles. The vertical arrow on the abscissa indicates the onset of movement.
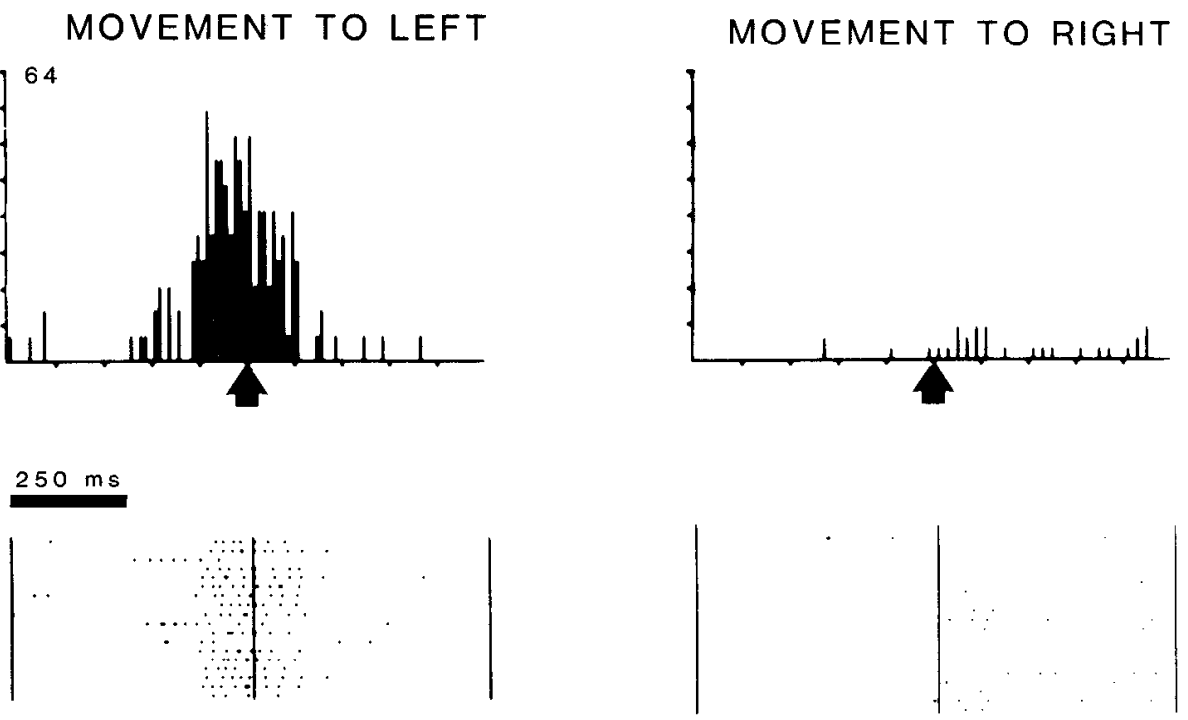

Figure 8. A directionally sensitive movement-related unit in the premotor cortex rastered on movement onset (arrow). The unit was active prior to leftward movements and did not change activity prior to rightward movements.

distal, and axial muscles. We have no reason to suppose that there was some specific muscle which was selectively active during the delay period. Of course, we cannot rule out the possibility that the set-related activity may reflect subthreshold changes in the excitability of spinal motoneurons and our conclusions must be tempered by this fact.

Mixed classes. A substantial proportion of cells (41\%) showed mixed activity patterns (see Table I). For example, 31 units showed combined signal-, movement-, and set-related activity. Twenty-two additional units showed signal- plus movement-related activity.

Units related to other aspects of behavior. Five units apparently related to saccadic eye movements were encountered in the premotor cortex. None of these cells had activity patterns resembling signal-, set-, or movement-related units. No units were encountered which showed a relationship to both arm and eye movement. The activity of 3 units was correlated with the occurrence of the water reward. These may have been related to licking or swallowing or may be interpreted as very late movement-related units. Two units showed increased activity during the inter-trial intervals and these have been classed as inhibitory set cells.

\section{Localization}

Movement-related units were found throughout the precentral gyrus. As illustrated by the solid circles in Figure $3 B$, many of these neurons were medial to the genu of the arcuate sulcus in the part of the frontal agranular cortex defined here as the premotor cortex. The premotor cortex was characterized by low giant pyramidal cell density (Fig. $4 B$ ) and high microstimulation thresholds (Fig. $3 A$ ). This same region contained 

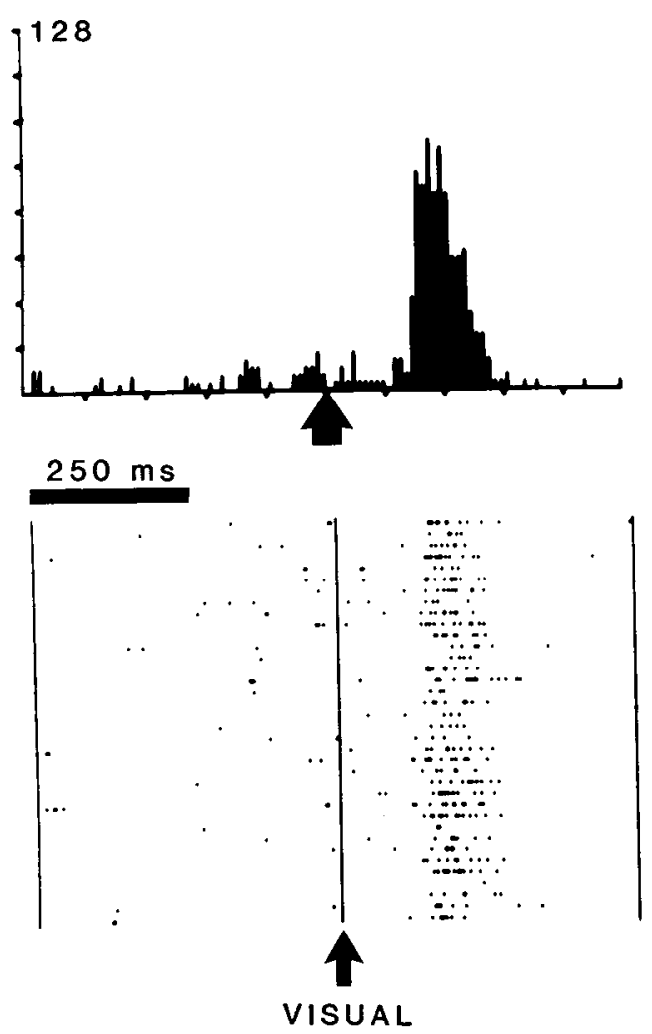

READY

SIGNAL

Figure 9. Signal-related neuron. A premotor unit with phasic discharge synchronized with the occurrence of the visual ready signal. Movement onset occurred off of the time scale of this display. This unit did not discharge in relation to movement, although many signal-related units did.

the vast majority of set- and signal-related units found in the present experiment. Penetrations which contained such units are illustrated with the open squares, triangles, and diamonds in Figure 3B. The apparent focus of movement-related units in the premotor cortex was found to be medial to the dorsal limb of the arcuate sulcus at approximately the rostrocaudal level of the arcuate genu. This region of concentrated task-related units extended from the penetration marked with the arrow in Figure 3 rostrally for 1.5 to $2 \mathrm{~mm}$ (see also Fig. 2).

\section{Discussion}

\section{The premotor cortex as a motor field}

The present data are consistent with a role for the premotor cortex in the control of movement and with the concept of a distinct premotor field which constitutes a part of the somatic sensorimotor cortex. A motor role for the premotor cortex gains support from the observation that the activity of the majority (73\%) of isolated neurons was synchronized with movement onset. Further, modulation over background activity levels was commonly profound, many units were directionally specific, and the onset of neuronal activity changes in movement-related units preceded muscle activity by at least as much time as in MI (cf., Fetz et al., 1980; Fromm, 1982). A motor role for the premotor cortex is also consistent with its proximity to and reciprocal connections with the MI representation (Matsumura and Kubota, 1979; Muakassa and Strick, 1979) and with its connectional and structural similarities to the accepted motor cortical fields, MI and the supplementary motor cortex (MII). The major efferent projections of the premotor cortex, to the red nucleus (Hartmann-von Monakow et al., 1979) and to the magnocellular nucleus of the medullary reticular formation (Kuypers and Lawrence, 1967), resemble other motor fields and support its assignment as one.

Previous behavioral investigations have supported a predominantly motor role for this field (Jacobsen, 1934; Bucy, 1933; Denny-Brown and Botterell, 1948; DennyBrown, 1966; Delacour et al., 1972; Moll and Kuypers, 1977; Deuel and Dunlop, 1979; see also Passingham, 1981). However, other studies have led to the conclusion that this region subserves cognitive functions, such as

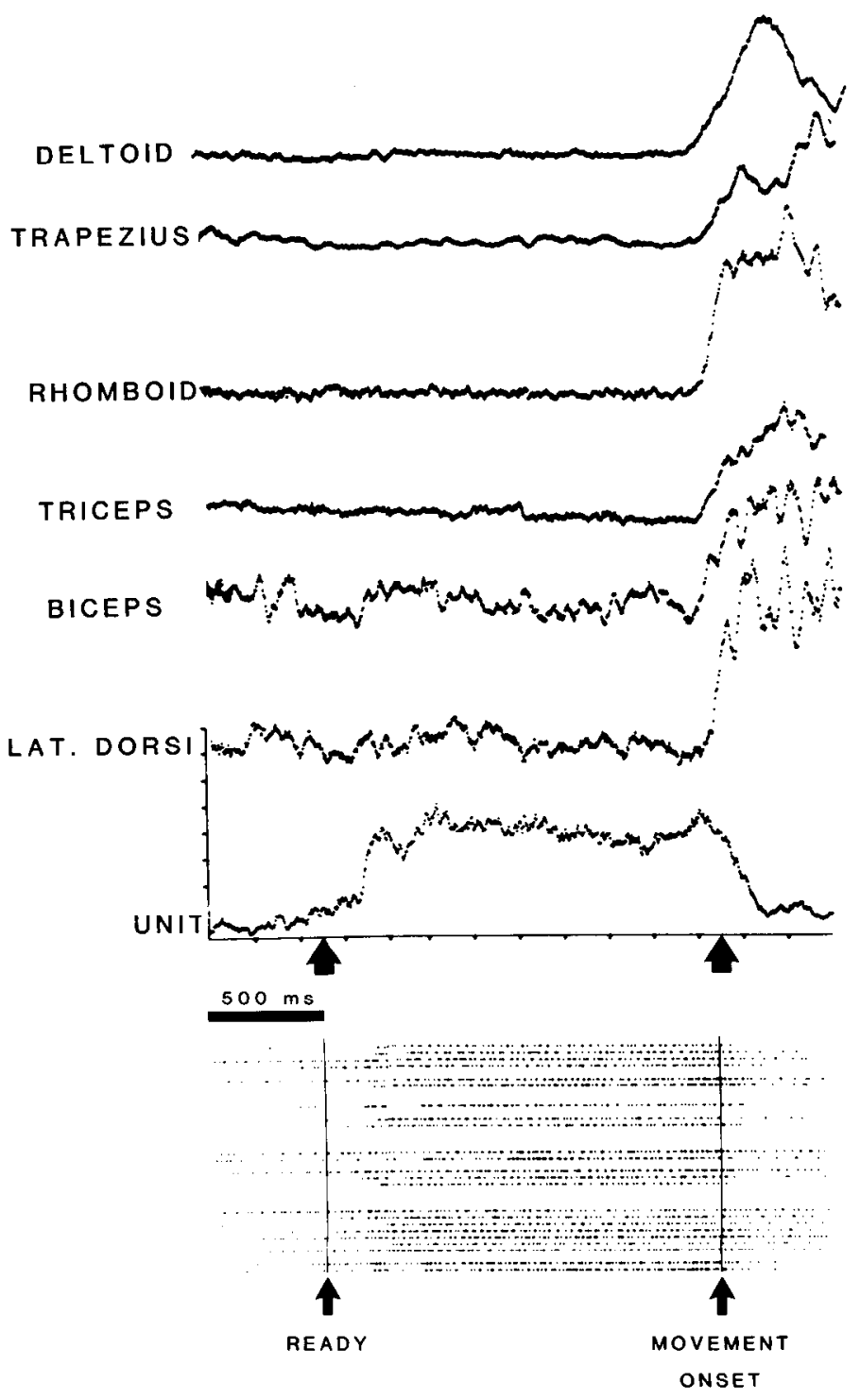

Figure 10. EMG activity during the delay period in six muscles compared with the activity of a set-related premotor unit. Note the absence of a transient or sustained EMG increase correlated with the appearance of the ready cue. 
the "assessment of meaningfulness" of polymodal sensory stimuli (Van Hoesen et al., 1980). In line with such a concept, Sakai (1978) suggested that units in this area were related to visual signals, reward contingency, and attention rather than to muscle contractions. However, the selected units for analysis that had only a weak modulation with exerted force. It is likely that Sakai (1978) sampled only a weakly related part of the premotor cortex. Furthermore, the units that he illustrated appear to be well correlated with the occurrence of a reward and he does not address the possibility that the observed unit activity may reflect motor preparation for reward. Of course, our data in no way contradict the idea of a cognitive plus motor role for the premotor cortex, but we feel that the evidence for a motor role is more compelling. In this regard, the observation of directional specificity among premotor cortex neurons is important. For movements to the same target from different directions, the visuospatial cues and reward contingency remained constant. Thus, such specificity demonstrates that the relationship of unit activity is to the movement performed (or planned) rather than the visuospatial cues per se or reward contingency.

Our data agree with those of Kubota and Hamada (1978), who reported that neurons in the premotor cortex are active prior to muscle activity and that many of these units show directional specificity, and with Godschalk et al. (1981), who showed the existence of signal- and movement-related neurons in the premotor cortex.

\section{The premotor cortex as a distinct cortical field: Comparison with other frontal fields}

The premotor cortex can be appreciated as a separate cortical field on the basis of a constellation of structural and physiological properties which serve to distinguish it from adjacent fields: MI, MII, and the frontal granular cortex. The possibility remains that the premotor cortex may contain more than one cortical field.

Contrasts with MI. The premotor cortex can be distinguished from MI on several grounds: the presence of higher intracortical microstimulation thresholds, the proportion of set- and signal-related units, and cytoarchitectonics. Microstimulation at low levels reliably elicits effects from MI. Premotor cortex stimulation at less than $60 \mu \mathrm{A}$ fails to produce observable responses. Our results are in accord with previous intracortical stimulation experiments in the premotor cortex (Sakai, 1978) and agree fairly well with the classical surface stimulation map of MI by Woolsey et al. (1952), considering the substantial amount of current spread to be expected with surface stimulation methods.

Visual signals are highly effective in evoking activity from many premotor cortex neurons (signal-related units, $43 \%$ ), while such "responses" are relatively rare (4\% of neurons sampled by Lamarre et al., 1981) in monkey MI cortex. Against this conclusion, Kwan et al. (1981) recently have reported "visual" effects in precentral cortex units which, in view of the low microstimulation thresholds that they report in the vicinity of those units, appear likely to be within the MI representation as we have defined it here. Unfortunately, they did not exclude, by EMG data, the startle effects which might be expected in their task and which might be reflected in cortical activity. Their data therefore are difficult to interpret. At the present time, we conclude from the present and previous studies (e.g., Kubota and Hamada, 1978; Godschalk et al., 1981; Rizzolatti et al., 1981a, b) that visuospatial signals affect a large population of premotor cortex units (the signal-related units), a feature which distinguishes it quantitatively from the MI representation. The rarity of substantial visual responsiveness of MI neurons in the monkey should not be confused with the more common responsiveness to visual stimuli of neurons in cat motor cortex (Garcia-Rill and Dubrovsky, 1974).

Set effects also may serve to distinguish the premotor cortex and MI. While set-related activity has been demonstrated in monkey motor cortex (Tanji and Evarts, 1976), such activity appears to be of higher amplitude in the premotor cortex than in MI. Further, set-related units were more commonly observed in the premotor cortex than in MI during performance of the present task. A quantitative comparison of motor set effects in MI and the premotor cortex is in progress, but preliminary results indicate that set effects are present in approximately 4- to 7-fold greater proportions in the premotor cortex.

Cytoarchitectural characteristics can distinguish MI and the premotor cortex, although no precise boundaries are observed (see "Results"). The microstimulation border (Fig. $3 A$ ) corresponds with the change in density of giant layer $V$ cells. These boundaries also agree with that drawn between the cortical fields designated FA and FB by von Bonin and Bailey (1947) in the rhesus monkey. This border agrees less closely with analogous borders drawn by Brodmann (1909; areas 6 and 4) and Vogt and Vogt (1919; areas $6 \mathrm{a} \alpha$ and $6 \mathrm{a} \beta)$ in another Old World monkey.

Units within the premotor cortex are relatively unresponsive to peripheral mechanical stimulation when compared to MI neurons (Brinkman and Porter, 1979a). This distinction also may be useful in identifying these areas.

Comparison with MII. MII and the premotor cortex share a number of physiological and anatomical properties. Signal-related units have been observed in MII (Tanji and Kurata, 1981) and are also prominent in the premotor cortex. Likewise, responses to somatosensory stimuli may be weak in both MII (Brinkman and Porter, 1979b; Wise and Tanji, 1981) and in the premotor cortex (Brinkman and Porter, 1979a). Microstimulation thresholds are higher for MII (Smith, 1979; Wise and Tanji, 1981; MacPherson et al., 1982) and the premotor cortex (Sakai, 1978; present report) than in MI. Tanji et al. (1980) demonstrated set-related activity in MII much like that reported here for the premotor cortex, although the magnitudes of such effects do not appear to approach those seen in the premotor cortex. These similarities, together with the cytoarchitectonic similarities of the premotor cortex and $\mathrm{MII}^{5}$ and the similarity of their

\footnotetext{
${ }^{5}$ Neuroanatomists such as Brodmann (1909), Vogt and Vogt (1919), and von Bonin and Bailey (1947) did not distinguish between regions comprising MII and the premotor cortex on cytoarchitectonic grounds.
} 

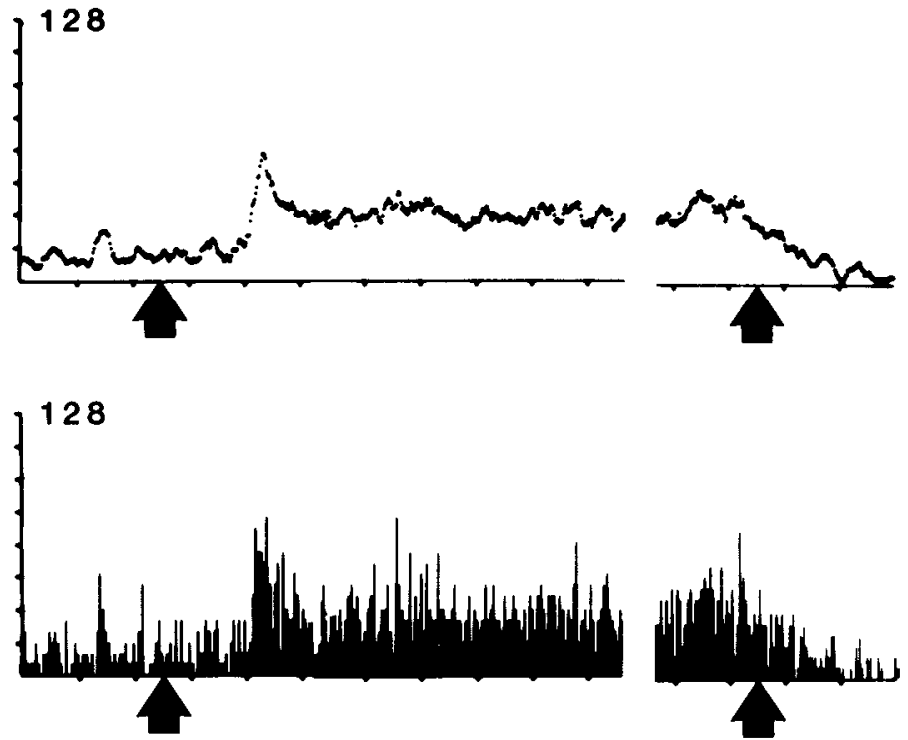

$250 \mathrm{~ms}$
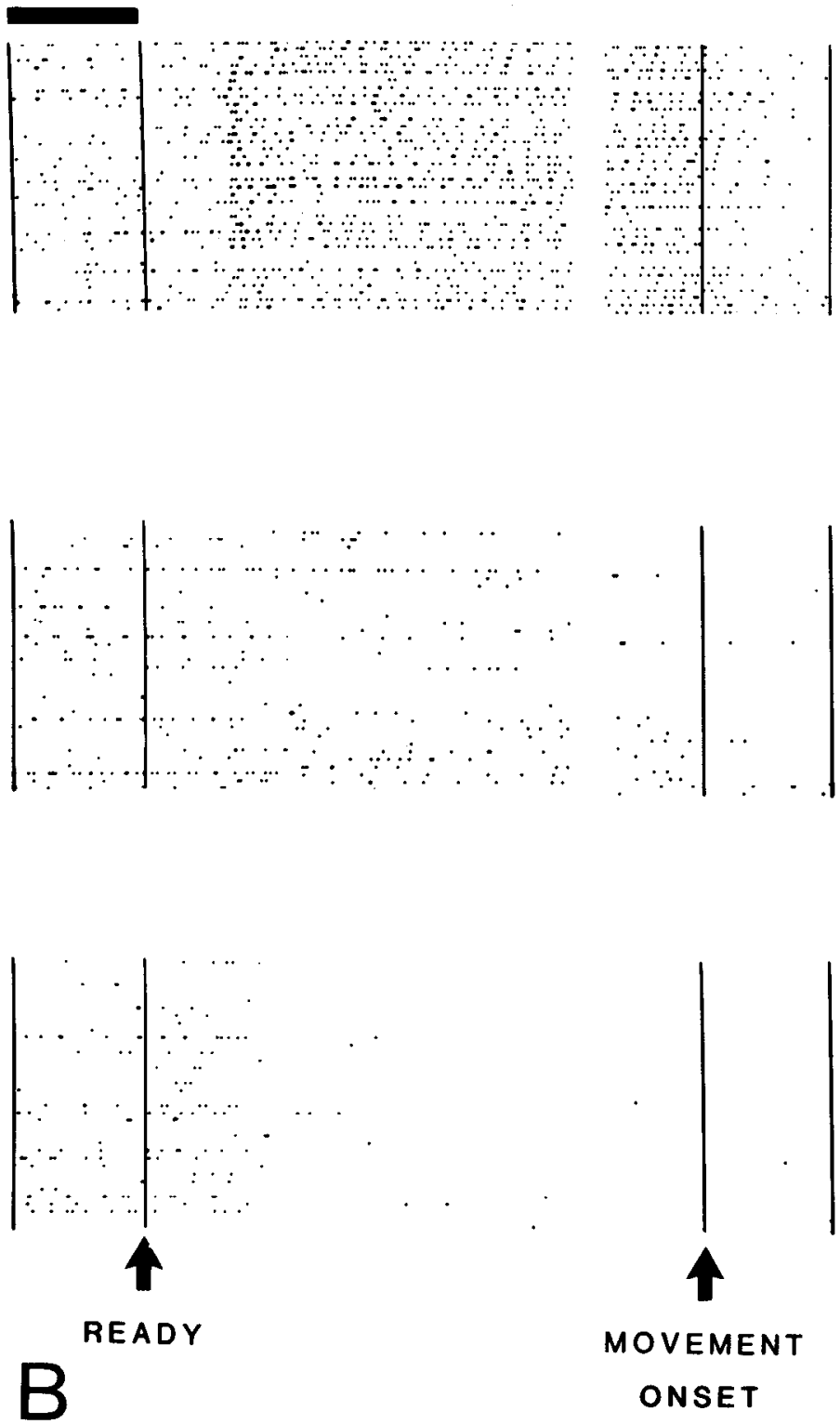

Figure 11. Continued. $B$, The same unit illustrated for movements to the other three targets. From top to bottom: middle
Several investigators (Fuster, 1973; Kubota et al., 1980; Bakay-Pragay et al., 1980) have suggested that the frontal cortex subserves a role in directing attention or generalized arousal. For example, Kubota et al. (1980) concluded "that the prefrontal cortex is related to a sensorial attention mechanism to the visual stimulus which enables correct choice of behavior to be rewarded." This conclusion is difficult to justify from the data that they present. More impressive is the fact that $40 \%$ of the neurons that they studied for movement relationships exhibited significant rate modulations synchronized with movement. Set cells, such as we observed, are unlikely to play a role in a generalized mechanism of attention since the majority of set-related units in the premotor cortex are directionally specific. They remain inactive prior to movements in the nonpreferred direction during which the attentional and arousal factors are presumably the same as for the preferred direction. To ascribe an attentional attribute to such activity, attention to a given target would have to occur only if movement was to be made in a specific direction to it.

\section{Role of premotor cortex in the neural control of movement}

A number of hypotheses have been advanced concerning the specific role of the premotor cortex in the control of movement. Humphrey (1979) suggested that the premotor cortex controls posture and orientation movements, mainly of proximal musculature (see also Bucy, 1933; Denny-Brown, 1966). Set-related units can readily be imagined to play a role in the postural preparation for specific movements. As pointed out under "Results", we cannot rule out the possibility that set-related activity reflects a motor command to an unmonitored muscle or to subthreshold motor commands not reflected in EMG activity. However, if the set-related units play a role in such postural maintenance, this role appears to be a rather specific one. The majority of set-related cells discharged only when the impending movement was to be in one direction and they were often dependent on the modality of the spatial cue.

A second view of nonprimary motor cortex function, stressed by Moll and Kuypers (1977), maintains that the premotor cortex inhibits direct arm projection movements, allowing implementation of more complex motor sequences (see also Passingham, 1981; Deuel and Dunlop, 1979; Rizzolatti et al., 1981a). The activity of both the movement- and set-related cells is consistent with this hypothesis. A third hypothesis is that the premotor cortex specifies the final target position of the arm, especially for a visually guided movement. We observed a few cells in the premotor cortex which appeared to be more active for movements to the center two targets (see Fig. 1), irrespective of movement direction, and thus may encode ultimate limb position. Unfortunately, the number of such cells that we observed was too small (4) to be conclusive and no single example was unequivocal. Geor-

left target (see Fig. 1), middle right, and far right. Note the absence of any change in activity when the monkey is instructed to move to the middle right target. 
VISUAL READY
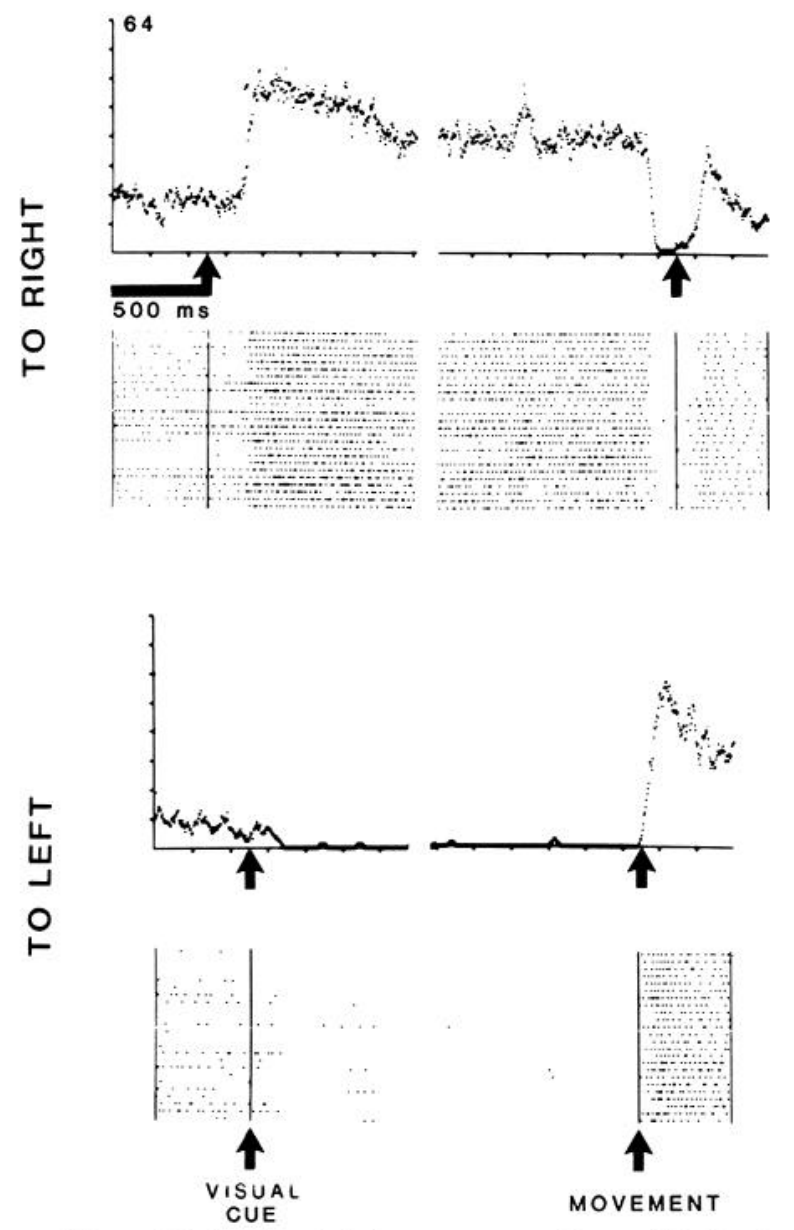

AUDITORY READY
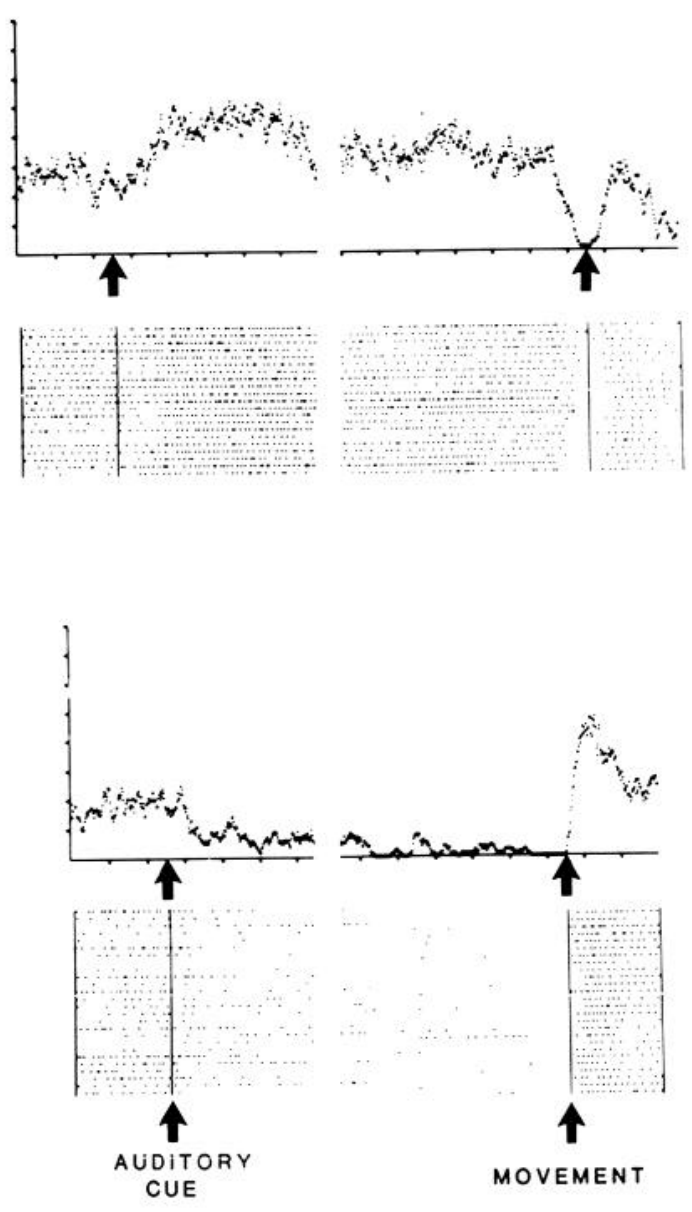

Figure 12. A set-related premotor unit specific for the instruction to move to the right. The unit is reciprocal (i.e., inhibited in the nonpreferred direction). The set-related activity is comparable when an auditory cue (right) is substituted for the visual ready cue $(l e f t)$.

gopoulos and his colleagues $(1980,1981)$ also have failed to find a convincing population of "position-encoding" cells.

A fourth idea is that the premotor cortex plays a specific role in sensorially guided movements. Benson et al. (1979) found that premotor cortex units were activated by visual and auditory cues only when motor responses to the cues were required. Signal- or set-related units may indeed play a role in visually guided or aurally guided movement, but it is difficult to put forward any concrete models for such a function at this time. Other investigators (Kubota et al., 1980; Godschalk et al., 1981) have made similar suggestions but also have been rather vague about the role of the premotor cortex in the control of visually guided movements. We would only add to these four ideas that the pattern of set-related activity may serve to decrease the reaction time by keeping spinal motor neurons and motor relay neurons, such as corticospinal and rubrospinal cells, nearer their firing threshold.

The similarities between unit activity patterns in the premotor and posterior parietal cortex are intriguing. Mountcastle et al. (1975) have reported patterns of activity in the posterior parietal cortex similar to our set-, signal-, and movement-related units as well as units related to visual fixation. We do not wish to speculate on the "command" properties of the premotor versus parietal cortex but simply to note that the efferent connections of the premotor cortex appear well suited to mediate motor output directly (see above). It may be helpful to consider the control of visually guided arm movement in a conceptual framework analogous to that of the physiology of language in man. In that system, it is commonly believed that two connected cortical fields function together in the motor tasks of language; a parietotemporal field (Wernicke's area) is thought to be concerned primarily with the integration of polymodal information, while a frontal field (Broca's area, rostrally adjacent to MI) is concerned primarily with the execution of speech (Geschwind, 1965). The monkey's premotor cortex may have a homologous role in the motor system to that of Broca's area in articulation and vocalization. 

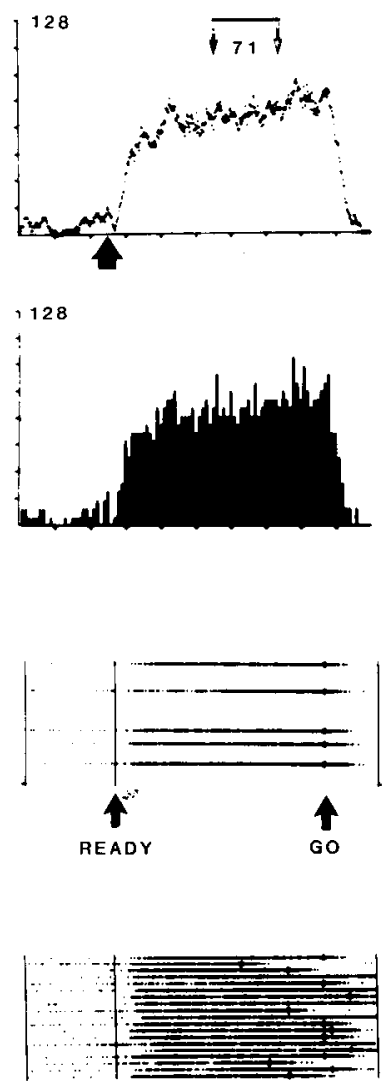
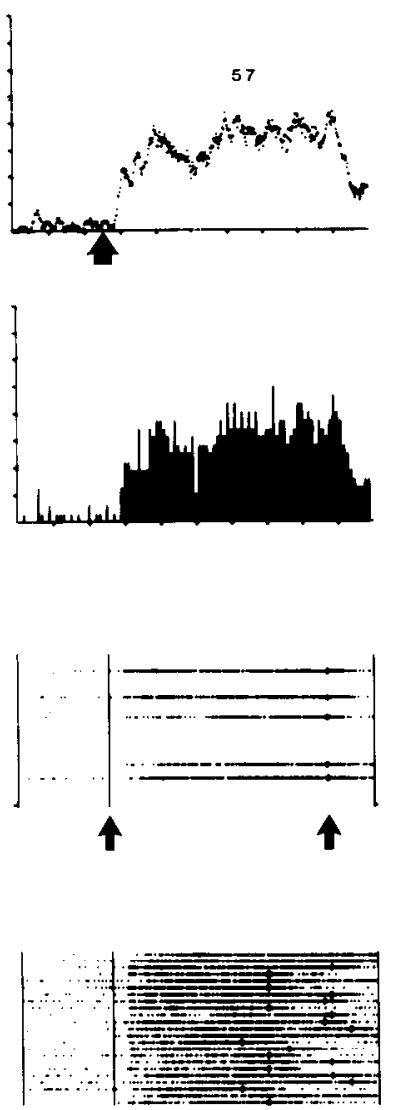
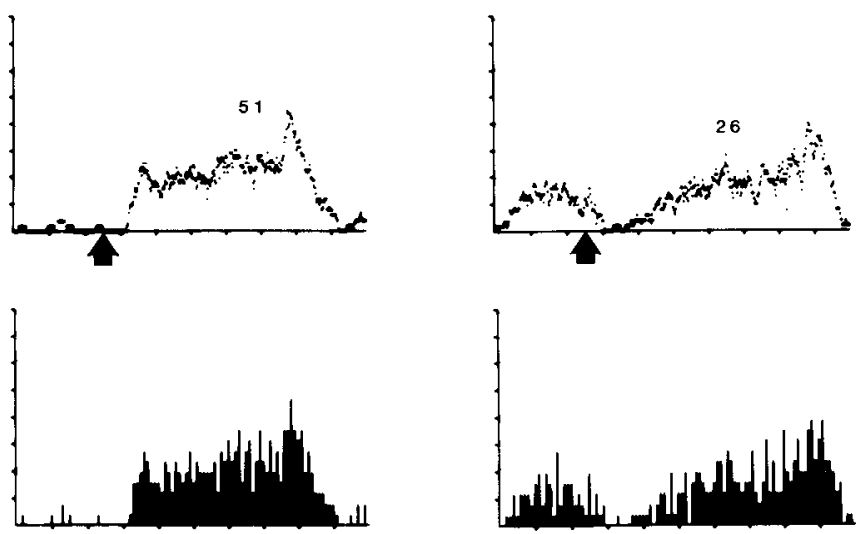
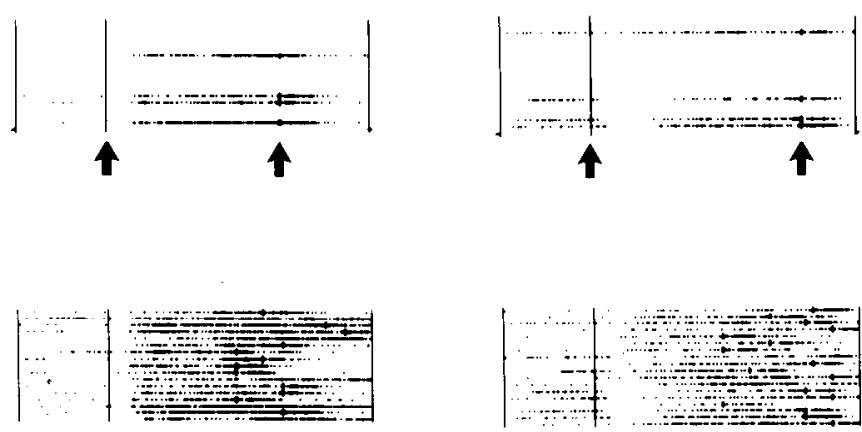

Figure 13. The most common type of set-related directional specificity encountered. The bottom line of rasters illustrates all trials for a given movement direction with each target position. The row of rasters above these shows trials of equal delay period for each target. This unit shows differential activity with respect to movement direction. The numbers above each average indicate mean activity (impulses per sec) during the period shown for the leftmost display.

\section{References}

Bakay-Pragay, E., A. F. Mirsky, C. V. Mirsky, and B. H. Scales (1980) Characteristics of attention-related cells in prefrontal cortical regions. Soc. Neurosci. Abstr. 6: 813.

Benson, D. A., R. D. Hienz, and M. H. Goldstein, Jr. (1979) Observations on unit activity in monkey auditory cortex and dorsolateral frontal cortex during a sound localization task. Soc. Neurosci. Abstr. 5: 16.

Brinkman, J., and R. Porter (1979a) 'Premotor' area of the monkey's cerebral cortex: Activity of neurones during performance of a learned motor task. Proc. Aust. Physiol. Pharmacol. Soc. 10: 198 .

Brinkman, C., and R. Porter (1979b) Supplementary motor area in the monkey: Activity of neurons during performance of a learned motor task. J. Neurophysiol. 42: 681-709.

Brodmann, K. (1909) Vergleichende lokalisationslehre der grosshirnrinde in ihren prinzipien dargestell auf Grund des Zellenbaues, J. A. Barth, Leipzig, Germany.

Bucy, P. C. (1933) Electrical excitability and cyto-architecture of the premotor cortex in monkeys. Arch. Neurol. Psychiatry 30: $1205-1224$.

Bucy, P. C. (1935) A comparative cytoarchitectonic study of the motor and premotor areas in the primate. J. Comp. Neurol. 62: 293-331.
Bucy, P. C., and J. F. Fulton (1933) Ipsilateral representation in the motor and premotor cortex of monkeys. Brain 56: 318-342.

Delacour, J., L. Iboubos, and M. McNeil (1972) Premotor cortex and instrumental behavior in monkeys. Physiol. Behav. 8: 299-305.

Denny-Brown, D. (1966) The Cerebral Control of Movement, Liverpool University Press, Liverpool, England.

Denny-Brown, D., and E. H. Botterell (1948) The motor functions of the agranular frontal cortex. Res. Publ. Assoc. Res. Nerv. Ment. Dis. 27: 235-345.

Deuel, R. K., and N. L. Dunlop (1979) Role of frontal polysensory cortex in guidance of limb movements. Brain Res. 169: 183-188.

Fetz, E. E., D. V. Finocchio, M. A. Baker, and M. J. Soso (1980) Sensory and motor responses of precentral cortex cells during comparable passive and active joint movements. J. Neurophysiol. 43: 1070-1089.

Fromm, C. (1982) Contrasting properties of pyramidal tract neurons arising from pre- and postcentral areas and of corticorubral neurons in the behaving monkey. In Motor Control Mechanisms in Man, J. E. Desmedt, ed., Raven Press, New York, in press.

Fulton, J. F. (1934) Forced grasping in relation to the syndrome of the premotor area. Arch. Neurol. Psychiatry 31: 221-235. 
Fuster, J. M. (1973) Unit activity in prefrontal cortex during delayed-response performance: Neuronal correlates of transient memory. J. Neurophysiol. 36: 61-78.

Garcia-Rill, E., and B. Dubrovsky (1974) Responses of motor cortex cells to visual stimuli. Brain Res. 82: 185-194.

Georgopoulos, A. P., J. F. Kalaska, and J. T. Massey (1980) Cortical mechanisms of two-dimensional aiming arm movements. I. Aiming at different target locations. Soc. Neurosci. Abstr. 6: 156.

Georgopoulos, A. P., J. F. Kalaska, R. Caminiti, and J. T. Massey (1981) Cortical mechanisms of two-dimensional aimed arm movements. V. Interactions between direction of movement and arm position in space. Soc. Neurosci. Abstr. 7: 563 .

Geschwind, N. (1965) Disconnexion syndromes in animals and man II. Brain 88: 585-644.

Godschalk, M., R. N. Lemon, H. G. T. Nijs, and H. G. J. M. Kuypers (1981) Behaviour of neurons in monkey peri-arcuate and precentral cortex before and during visually guided arm and hand movements. Exp. Brain Res. 44: 113-116.

Goldberg, M. E., and C. J. Bruce (1981) Frontal eye fields in the monkey: Eye movements remap the effective coordinates of visual stimuli. Soc. Neurosci. Abstr. 7: 131.

Hartmann-von Monakow, K., K. Akert, and H. Künzle (1979) Projections of precentral and premotor cortex to the red nucleus and other midbrain areas in Macaca fascicularis. Exp. Brain Res. 34: 91-105.

Humphrey, D. R. (1979) On the cortical control of visually directed reaching: Contributions by non-precentral motor areas. In Posture and Movement, R. E. Talbott and D. R. Humphrey, eds., pp. 51-112, Raven Press, New York.

Jacobsen, C. F. (1934) Influence of motor and premotor areas lesions upon retention of skilled movements in monkeys and chimpanzees. Res. Publ. Assoc. Nerv. Ment. Dis. 13: 225-247.

Jones, E. G., J. D. Coulter, H. Burton, and R. Porter (1977) Cells of origin and terminal distribution of corticostriatal fibers arising in the sensory-motor cortex of monkeys. J. Comp. Neurol. 173: 53-80.

Kubota, K., and I. Hamada (1978) Visual tracking and neuron activity in the post-arcuate area in monkeys. J. Physiol. (Paris) 74: 297-312.

Kubota, K., and H. Niki (1971) Prefrontal cortical unit activity and delayed alternation performance in monkeys. J. Neurophysiol. 34: 337-347.

Kubota, K., T. Iwamoto, and H. Suzuki (1974) Visuokinetic activities of primate prefrontal neurons during delayed-response performance. J. Neurophysiol. 37: 1197-1212.

Kubota, K., M. Tonoike, and A. Mikami (1980) Neuronal activity in the monkey dorsolateral prefrontal cortex during a discrimination task with delay. Brain Res. 183: 29-42.

Kuypers, H. G. J. M., and D. G. Lawrence (1967) Cortical projections to the red nucleus and the hrain stem in the rhesus monkey. Brain Res. 4: 151-188.

Kwan, H. C., W. A. MacKay, J. T. Murphy, and Y. C. Wong (1978) Spatial organization of precentral cortex in awake primates. II. Motor outputs. J. Neurophysiol. 41: 1120-1131.

Kwan, H. C., W. A. MacKay, J. T. Murphy, and Y. C. Wong (1981) Distribution of responses to visual cues for movement in precentral cortex of awake primates. Neurosci. Lett. 24: 123-128.

Lamarre, Y., G. Spidalieri, and J. D. Lund (1981) Patterns of muscular and motor cortical activity during simple arm movement in the monkey. Can. J. Physiol. Pharmacol. 59: $748-756$.

MacPherson, J., C. Marangoz, T. S. Miles, and M. Wiesendanger (1982) Microstimulation of the supplementary motor area (SMA) in the awake monkey. Exp. Brain Res. 45: 410-416.

Matsumura, M., and K. Kubota (1979) Cortical projection to hand-arm motor area from post-arcuate in macaque monkeys: A histological study of retrograde transport of horseradish peroxidase. Neurosci. Lett. 11: 241-246.

Moll, L., and H. G. J. M. Kuypers (1977) Premotor cortical ablations in monkeys: Contralateral changes in visually guided reaching behavior. Science 198: 317-319.

Mountcastle, V. B., J. C. Lynch, A. Georgopoulos, H. Sakata, and C. Acuna (1975) Posterior parietal cortex in the monkey: Command functions for operations within extrapersonal space. J. Neurophysiol. 38: 871-908.

Muakassa, K. F., and P. L. Strick (1979) Frontal lobe inputs to primate motor cortex: Evidence for four somatotopically organized 'premotor' areas. Brain Res. 177: 176-182.

Niki, H. (1974a) Prefrontal unit activity during delayed alteration in the monkey. I. Relation to direction of response. Brain Res. 68: 185-196.

Niki, H. (1974b) Prefrontal unit activity during delayed alteration in the monkey. II. Relation to absolute versus relative direction of response. Brain Res. 68: 197-204.

Niki, H. (1974c) Differential activity of prefrontal units during right and left delayed response trials. Brain Res. 70: 346-349.

Niki, H., and M. Watanabe (1979) Prefrontal and cingulate unit activity during timing behavior in the monkey. Brain Res. 171: 213-224.

Passingham, R. E. (1981) Broca's area and the origins of human vocal skill. Philos. Trans. R. Soc. Lond. (Biol.) 292: 167-175.

Rizzolatti, G., C. Scadolara, M. Matelli, and M. Gentilucci (1981a) Afferent properties of periarcuate neurons in macaque monkeys. II. Visual responses. Behav. Brain Res. 2: 147-163.

Rizzolatti, G., C. Scandolara, M. Gentilucci, and R. Camarda (1981b) Response properties and behavioral modulation of "mouth" neurons of the postarcuate cortex (area 6) in macaque monkeys. Brain Res. 225: 421-424.

Roland, P. E., E. Skinhoj, N. A. Lassen, and B. Larsen (1980) Different cortical areas in man in organization of voluntary movements in extrapersonal space. J. Neurophysiol. 43: 137-150.

Sakai, M. (1974) Prefrontal unit activity during visually guided lever pressing reaction in the monkey. Brain Res. 81: 297-309.

Sakai, M. (1978) Single unit activity in a border area between the dorsal prefrontal and premotor regions in the visually conditioned motor task of monkeys. Brain Res. 147: 377-383.

Smith, A. M. (1979) The activity of supplementary motor area neurons during a maintained precision grip. Brain Res. 172: 315-327.

Suzuki, N., and M. Azuma (1977) Prefrontal neuronal activity during gazing at a light spot in the monkey. Brain Res. 126: 497-508.

Tanji, J., and E. V. Evarts (1976) Anticipatory activity of motor cortex neurons in relation to direction of an intended movement. J. Neurophysiol. 39: 1062-1068.

Tanji, J., and K. Kurata (1981) Neuronal activity in two cortical motor representation areas associated with quick wrist movements. Neurosci. Lett. Suppl. 6: S22.

Tanji, J., K. Taniguchi, and T. Saga (1980) The supplementary motor area: Neuronal responses to motor instructions. J. Neurophysiol. 43: 60-68.

Van Hoesen, G. W., A. V. Brent, D. N. Pandya, and T. M. McKenna (1980) Compound stimulus differentiation behavior in the rhesus monkey following periarcuate ablations. Brain Res. 186: 365-378.

Vogt, O., and C. Vogt (1919) Ergebisse unserer Hirnforschung. J. Psychol. Neurol. Lpz. 25: 277-462.

von Bonin, G., and P. Bailey (1947) The Neocortex of Macaca Mulatta, University of Illinois Press, Urbana, IL.

Wiesendanger, M. (1981) Organization of secondary motor areas of cerebral cortex. In Handbook of Physiology. Section I: 
The Nervous System. Vol. II: Motor Control, part 2, pp. 1121-1147, V. B. Brooks, ed., American Physiological Society, Bethesda, MD.

Wise, S. P., and J. Tanji (1981) Supplementary and precentral motor cortex: Contrast in responsiveness to peripheral input in the hindlimb area of the unanesthetized monkey. J. Comp.
Neurol. 195: 433-451.

Woolsey, C. N., P. H. Settlage, D. R. Meyer, W. Sencer, T. Pinto Hamuy, and A. M. Travis (1952) Patterns of localization in precentral and "supplementary" motor areas and their relation to the concept of a premotor area. Res. Publ. Assoc. Res. Nerv. Ment. Dis. 30: 238-264. 